\title{
不凝縮ガスによるマイクロ蒸気インジェクタの性能劣化改善*
}

\author{
才原淳*1, 堀木 幸 代*2, 刑 部 真 弘*3 \\ 森治 嗣 ${ }^{* 4}$, 大森修一*5
}

\section{Improvement of Degradation with Non-condensable Gas in Micro Steam Injector}

\author{
Atsushi SAIHARA, Sachiyo HORIKI, Masahiro OSAKABE*6, \\ Michitsugu MORI and Shuichi OHMORI
}

\footnotetext{
${ }^{* 6}$ Department of Marine Electronics and Mechanical Engineering, Tokyo University of Marine Science and Technology, 2-1-6 Etchujima, Koto-ku, Tokyo, 135-8533 Japan
}

\begin{abstract}
Effect of non-condensable gas on a micro steam injector (MSI) to obtain a vacuum was experimentally studied. When a pure steam was used in the MSI, the high vacuum condition was obtained. However when the mass fraction of air included in the steam was larger than a cartain value, the MSI became unstable and the vacuum condition could not be obtained. It is considered that the malfunction is due to the instability triggered with the uncondensed steam remained at the throat in downstream of the condensing region. The water nozzle was expected to be a key component to mitigate the effect of non-condensable gas. Three kinds of water nozzle whose flow areas were round, star and screw shapes were used in the present experiment. The star-shaped nozzle where the increased surface area could be expected to compensate the degradation of condensation failed to improve the malfunction of MSI with the non-condensable gas. The screw nozzle expected to drive air away outside the condensing surface could mitigate the effect of non-condensable gas.
\end{abstract}

Key Words: Steam Injector, Non-condensable Gas, Vacuum Generation, Water Nozzle Shape

\section{1. 緒}

蒸気インジェク夕(Steam Injector : SI)は, 蒸気駆動さ れる静的な噴流ポンプであると同時に，真空生成や直 接接触熱交換器としても用いられるコンパクトでシ ンプルな機器である.このため, 原子力発電プラント の設備簡素化·コス卜低減を目指して炉心注水系や給 水加熱系への適用を中心に開発が進められている. 特 に, 原子力発電プラントの給水加熱系に適用した場合, 給水加熱器本体の小型化や建屋必要容積の低減, 定検 時の保守点検作業軽減などの大きなメリットがある と期待される(1) (2).

しかし, 蒸気インジェクタの駆動源である蒸気の中 に少しでも不凝縮ガス (空気等) が混入していると， 超音速蒸気流の水噴流への直接凝縮に大きな影響を

* 原稿受付 2006 年 10 月 12 日.

*1 学生員, 東京海洋大学大学院海洋科学技術研究科 ( 135 8533 東京都江東区越中島 2-1-6).

*2 正員, 東京海洋大学海洋工学部.

*3 正員, フェロー, 東京海洋大学海洋工学部.

*4 正員, フェロー, 東京電力(株) 技術開発研究所 (五 230-8510 横浜市鶴見区江ヶ崎 4-1).

*5 正員, 東京電力(株) 技術開発研究所.

E-mail : osakabe@ kaiyodai.ac.jp
与えるため, 蒸気インジェクタが正常に作動しなくな る場合がある.これは, 蒸気インジェク夕を特に火力 発電プラントへ適用する際に懸念されるが, 給水中や ボイラーで発生する主蒸気中に含まれる不凝縮ガス が, 蒸気インジェクタの凝縮熱伝達や混合ノズル内の 真空度に与える影響については, 試験や理論的評価が 充分になされているとは言えない状況にある. また， 蒸気インジェク夕は真空生成のために洗浄や食品乾 燥機等において用いられることも多いが，この場合に も不凝縮ガスが真空度に与える影響は重要である.

本研究では, この不凝縮ガスによる影響を緩和する 方法として, 水噴流形状に注目した性能向上検討を行 い, 蒸気インジェク夕の高性能化を目指した.

\section{2. 記号·単位}

$$
\begin{array}{ll}
A & : \text { 面積 }\left[\mathrm{mm}^{2}\right] \\
g_{0} & : \text { 標準重力加速度 }\left[=9.80665 \mathrm{~m} / \mathrm{s}^{2}\right] \\
j & : \text { 流速 }[\mathrm{m} / \mathrm{s}] \\
P & : \text { 圧力 }[\mathrm{MPa}] \\
r & : \text { 水ノズル半径 }[\mathrm{mm}] \\
T & : \text { 温度 }\left[{ }^{\circ} \mathrm{C}\right]
\end{array}
$$




$$
\begin{aligned}
& W \text { : 質量割合 }[\%] \\
& \omega \text { : 回転数 }[\mathrm{rad} / \mathrm{s}]
\end{aligned}
$$

\section{添字}

$$
\begin{array}{ll}
g & \text { : 不凝縮ガス } \\
M & \text { : 空気) } \\
S & \text { : 蒸気 } \\
W & : \text { 水 }
\end{array}
$$

\section{3. 実検装是および計测方法}

図 1 に実験装置概略図を示す，実験では, 蒸気イン ジェク夕内部に水, 蒸気, 空気を供給した. 水は地下 の水タンクから冷却水ポンプにより供給され, 浮子式 流量計にて水流量を調整した後, 蒸気インジェクタへ 供給した. 空気はコンプレッサーから供給され，減圧 弁において規定の圧力に減圧し, 浮子式流量計にて空 気流量を計測した後, 蒸気インジェクタへ供給した. 蒸気は電気ボイラから供給され，ボイラ元弁は全開と し, 蒸気インジェク夕に入る直前のバルブを開閉する ことによって蒸気流量の調整を行った. 蒸気流量は差 圧式マス Vコーンフローメータによって計測した. 各 流量の計測精度は指示值の $\pm 2 \%$ である.

蒸気インジェク夕内部で混合された水と蒸気は, 起 動時にはドレン側へと流れ，性能発揮時にはドレン側 へは流れず，出口側の排出タンクへと送られ，外部へ 排出される. 図中の $\mathrm{T}$ は外径 $1 \mathrm{~mm}$ の $\mathrm{T}$ 型シース熱電 対で, 蒸気入口温度, 水入口温度, ドレン管温度, 出 口温度を計測した. P はデジタル圧力計であり, 蒸気 入口圧力, 水入口圧力, ドレン管圧力, 出口圧力を計 測した. 温度計測誤差は $\pm 0.1 \mathrm{~K}$, 圧力測定誤差は $\pm 1.8 \mathrm{kPa}$ である.

図 2 に本研究で用いた水噴流中心形の蒸気インジェ ク夕の内部概念図を示す. 出口直径 $3.15 \mathrm{~mm}$ の水ノズ ルから水を噴出し, そこに超音速流の蒸気を凝縮させ る. ボイラから送られた蒸気は, 水ノズルとスリーブ との間に形成された末広部で超音速に加速され凝縮 混合部へと流れる. なお, 水ノズル出口外径とスリー ブ内径のなす面積を蒸気通過出口面積 $A_{S}$ とした. 正常 に作動している場合には, 蒸気はスリーブのど部まで の長さ約 $50.0 \mathrm{~mm}$ の水噴流の表面にすべて凝縮する. また, スリーブのど部から上流 $21 \mathrm{~mm}$ の場所にドレン 孔があり, 起動時で凝縮混合部圧力が大気圧以上の場 合はここから流体が排出される. 大気圧以下になると 逆止弁により外部から隔離される構造となっている. 凝縮混合部圧力は, 逆止弁手前のドレン管内に設置し

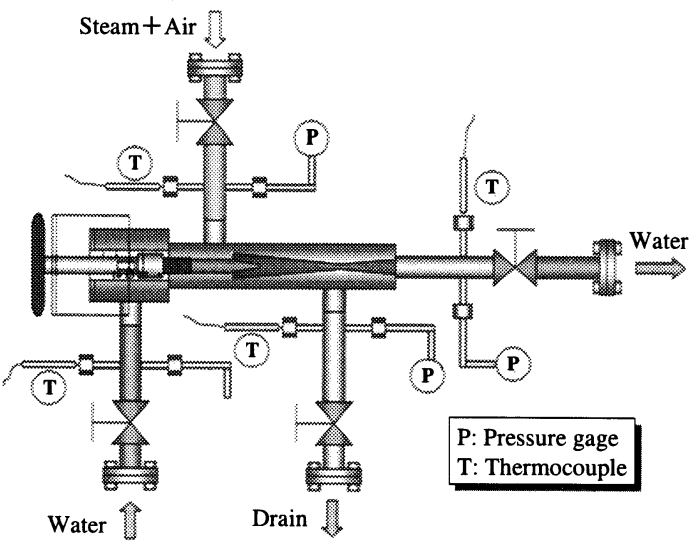

Fig. 1 Experimental apparatus

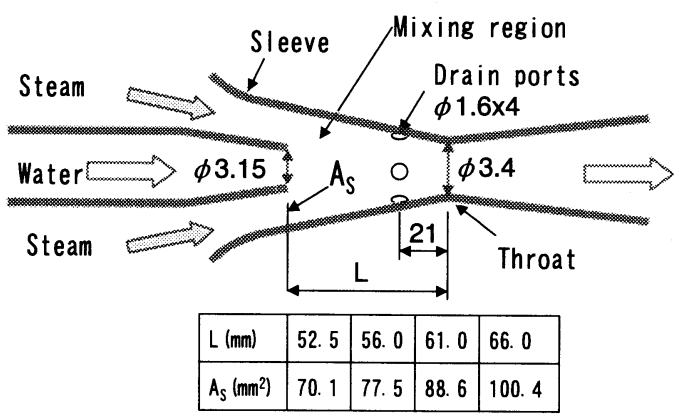

Fig. 2 Schematic of steam injector

た圧力計により計測した. なお, 水ノズルは水平にス ライド可能なため, 水ノズルからスリーブのど部まで の距離 $L$ および蒸気通過出口面積 $A_{S}$ を変化させるこ とができる. 図 2 中に示すように, 本実験では $L$ およ び $A_{S}$ の組み合わせを 4 種類とした.

混合ノズルの出口では, 超音速流の蒸気から運動量 を受けて高速水噴流となり，のど部下流のディフュー ザ内で速度エネルギーが圧力エネルギーに変換され る. 本研究ではSI の真空生成能力に注目したため, 出 口部は大気開放とした実験を行った。

図3に既存の円型ノズルと星型ノズルの比較を示す. 円型ノズルの水噴流断面積は $A_{W}=7.79 \mathrm{~mm}^{2}$, 星型ノズ ルは $A_{W}=12.05 \mathrm{~mm}^{2}$ である. 星型ノズルでは, 水ノズル 出口を星型にし，水ジェット界面を平滑ではなく波状 とすることで蒸気の凝縮面積を増大させ, 不凝縮ガス による凝縮熱伝達率の低下を補う. 星型ノズル断面の 一点鎖線で示した円が円形ノズル内径である.

旋回ノズルは, 円型水ノズル内部に異なるピッチの 渦流棒を挿入したものであり、出口水噴流に回転流れ を持たせることができる.図4に旋回ノズルの概念図, 


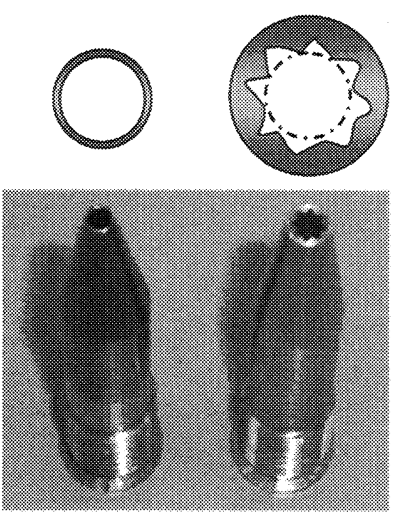

Fig. 3 Water nozzles

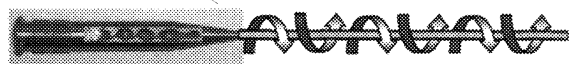

Fig. 4 Screw nozzle

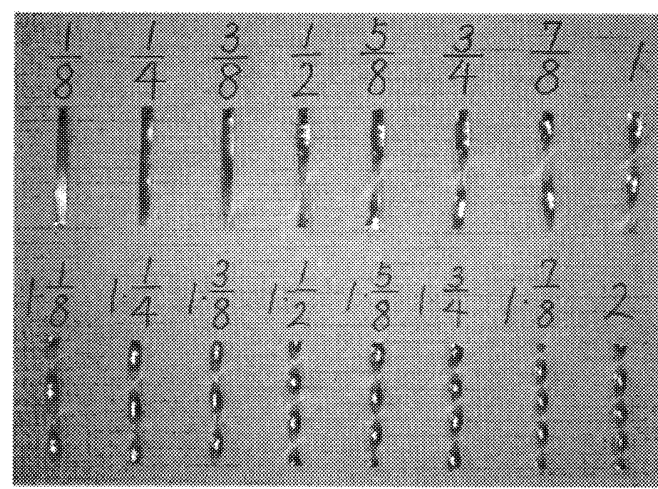

Fig. 5 Screw strips

図 5 に水ノズル中に挿入した 16 本の渦流棒を示す. 水ノズル内部に挿入した渦流棒により水噴流に回転 力を与え, 凝縮面近傍の空気を遠心力で外側へと拡散 させ, 蒸気の水噴流表面への凝縮を妨げる力を緩和さ せることを期待したものである.

\section{4. 実験方法}

最初に, 流量調整した水を混合ノズル内部へ流し, そこに超音速流の蒸気を噴出させて蒸気インジェク 夕を作動状態にした. 蒸気流量を多くすると蒸気の凝 縮する界面の温度が上昇し, 蒸気の水噴流表面への凝 縮が鈍くなる. 本実験では, 設計上の適切な蒸気流量 である $6.94 \times 10^{-3} \mathrm{~kg} / \mathrm{s}$ とした. 次に, 蒸気中に混入さ せる空気流量を增加させ, 不作動になるまで観察を行
った. 円型ノズル, 星型ノズル, 旋回ノズルの実験条 件を表 1 に示す.

\section{5. 実験結果及ひ考察}

$5 \cdot 1$ 可視化実殹 外側スリーブを透明アクリ ル製とした通常の円形水ノズルを用いた可視化実 験を行い, 混合部内部の流動状況を観察した. 図 6 は, 蒸気インジェクタが安定して作動している 状況であり, 混合部における凝縮界面は非常に安 定していた．また，スリーブのど部を過ぎても噴 流表面は白く, 薄い蒸気または空気層が存在して いる可能性が示唆された.

図 7 は, 水流量過少または不凝縮ガス濃度過多 により不作動となった状況を示す. 界面は非常に 不安定であり, 激しい圧力振動をともなった流れ となる. 水流量過少の場合には噴流表面温度の上 昇, 不凝縮ガス濃度過多の場合には凝縮伝熱の劣 化により，スリーブのど部までに凝縮できなかっ た蒸気がこの不安定を生じさせていると考えられ た. 不凝縮ガスが少しでも混入すると, 凝縮熱伝 達率は純蒸気に比べて, 大きく減少することが不

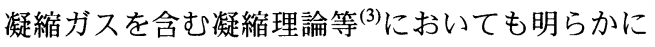
なっている.

Table 1 Experimental condition of a round, star-shaped and screw water nozzle experiments

\begin{tabular}{|l|l|}
\hline Steam flow rate $(\mathrm{kg} / \mathrm{s})$ & $6.94 \times 10^{-3}$ \\
\hline Steam nozzle outlet area $A_{S}\left(\mathrm{~mm}^{2}\right)$ & $70.1,77.5$, \\
& $88.6,100.4$ \\
\hline Distance to throat $L(\mathrm{~mm})$ & $52.5 \sim 66.0$ \\
\hline Water velocity $(\mathrm{m} / \mathrm{s})$ & $5.3 \sim 24.6$ \\
\hline Water temperature $\left({ }^{\circ} \mathrm{C}\right)$ & $4.4 \sim 24.0$ \\
\hline
\end{tabular}

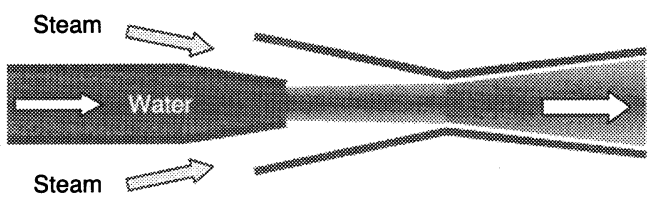

Fig. 6 Stable operation

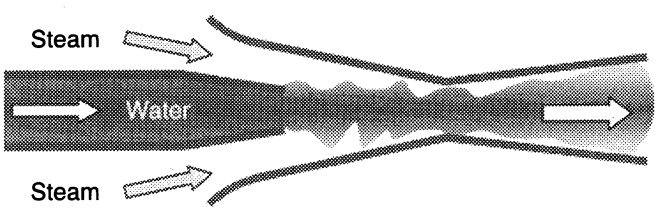

Fig. 7 Malfunction due to the less water flow or too much non-condensable gas 
5 -2 円型ノスルと星型ノズの比較実験 図 8 に 円型ノズルと星型ノズルの混合部圧力 $P_{M}$ と空気質量 割合 $W_{g}$ の関係を示す. 実験は, 蒸気通過出口面積 $A_{S}=77.5 \mathrm{~mm}^{2}$, 水流速 $j_{W}=17.1 \mathrm{~m} / \mathrm{s}$, 給水温度 $T_{W}=19.6 \sim$ $20.6^{\circ} \mathrm{C}$ 範井で行った. 空気質量割合 $W_{g}$ が增加するに 従い混合部圧力は徐々に上昇して行き, 混合部圧力が 大気圧 $(0.1 \mathrm{MPa})$ 以上に急増している場所で不作動とな った.

円型ノズルは $W_{g}=0.97 \%$, 星型ノズルは $W_{g}=0.19 \%$ ま で安定に作動することができたことが分かる. 星型ノ ズルの水噴流断面積 $A_{W}=12.05 \mathrm{~mm}^{2}$ は波状部の分だけ 円型ノズル $A_{W}=7.79 \mathrm{~mm}^{2}$ より大きく, 同じ水流速で比 較した場合, 供給される水流量が大きく水噴流表面が 低く保たれるため, 凝縮は円型ノズルよりも星型ノズ ルの方が促進されると考えられる. 実際に $W_{g}=0.19 \%$ 以下の領域においては，星型ノズルの方が，混合部圧 力 $P_{M}$ が低く高い凝縮能力を示している. しかし，実 際に安定作動する最大空気質量割合の值は, 星型ノズ ルが円型ノズルの 5 分の 1 程度になった. この一つの

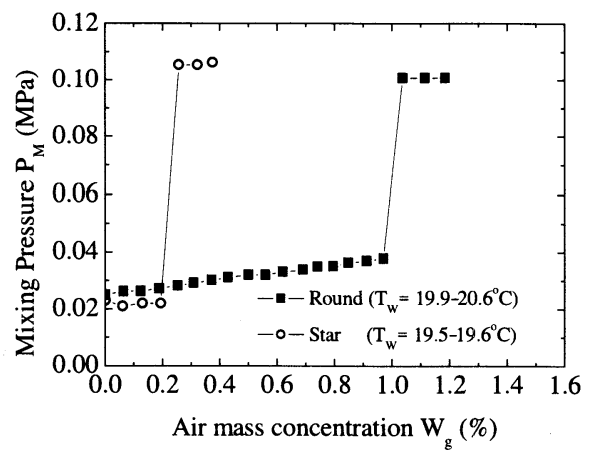

Fig. 8 Relation between air mass concentration and mixing pressure (round and star)

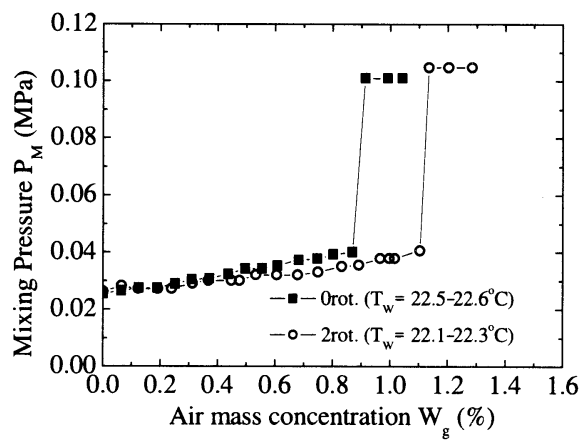

Fig. 9 Relation between air mass concentration and mixing pressure(round and screw)
理由として, 星型の断面から噴出された水噴流の表面 が波状の構造を形成することによって, 不凝縮ガスで ある空気の凝縮面からの拡散が制限され，蒸気の水噴 流表面への凝縮を妨げられることが考えられる. そこ で, 凝縮面近傍の空気を排除する構造を考え, 作成し たのが旋回ノズルである.

$5 \cdot 3$ 円型ノスルと旋回ノスルの比較実跧 図9に 0 回転の円型ノズルと 2 回転の旋回ノズルの混合部圧 力 $P_{M}$ と空気質量割合 $W_{g}$ の関係を示す. 実験は, 蒸気 通過出口面積 $A_{S}=77.5 \mathrm{~mm}^{2}$, 水流速 $j_{W}=17.1 \mathrm{~m} / \mathrm{s}$, 給水温 度 $T_{W}=22.1 \sim 22.6^{\circ} \mathrm{C}$ 範囲で行った. 0 回転の円型ノズ ル, 2 回転の旋回ノズル共に空気質量割合が増加する に従い混合部圧力は徐々に上昇して行き, $P_{M}=$ $0.04 \mathrm{MPa}$ 以上になると蒸気インジェク夕は不作動とな った. また, 安定作動する最大空気質量割合は 2 回転 の旋回ノズルの方が大きい. 水噴流に回転力を与えた ことで, 蒸気より重い空気が外側へと排除され，蒸気 の水噴流表面への凝縮を妨げる力が小さくなり, 凝縮 が促進されることが一つの理由として考えられる.

図 10 に実験で使用した渦流棒を示す．流れ方向長 さ $66.3 \mathrm{~mm}$ で 2 回転捻ったものを使用した.この場合, 水流速 $j_{W}=17.1 \mathrm{~m} / \mathrm{s}$ とすると旋回流の回転数は,

$$
\omega=2 \pi \frac{17.1}{0.03315}=3239(\mathrm{rad} / \mathrm{s})
$$

水噴流表面の凝縮面における遠心力は, 水ノズル半径 $r=3.15 / 2 \mathrm{~mm}$ として標準重力加速度 $g_{0}$ で無次元化する と

$$
\frac{r \omega^{2}}{g_{0}}=1686
$$

すなわち，この旋回ノズルを使用すると，すべりや減 衰等のない理想状態では, 重力加速度の約 1686 倍の 遠心力を生じさせることが可能である.このため, 凝 縮面近傍の空気が外側へと排除され，蒸気の水噴流表 面への凝縮を妨げないことが期待される.

5.4 円型ノスルと旋回ノズルの水流速実殹 図 11 に 0 回転の円型ノズルと 2 分の 1 回転の旋回ノズルの 最大作動空気質量割合 $W_{g}$ と水流速 $j_{W}$ の関係を示す.

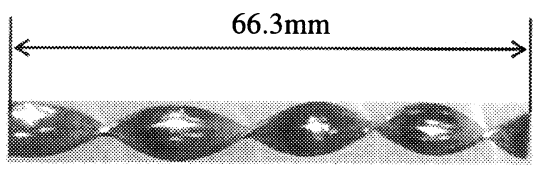

Fig. 10 Screw strip 
この実験は, 蒸気通過出口面積 $A_{S}=77.5 \mathrm{~mm}^{2}$, 水流速 $j_{W}=5.3 \sim 24.6 \mathrm{~m} / \mathrm{s}$, 給水温度 $T_{W}=4.4 \sim 22.8^{\circ} \mathrm{C}$ の範囲で行 った. 円型ノズルおよび旋回ノズル共に水流速が速く なるに従い, 最大作動空気質量割合が徐々に大きくな る.これは, 水流速が速くなることで供給される水流 量が多くなり，蒸気の凝縮する界面の温度が低下して， 蒸気の水噴流表面への凝縮が促進されるためだと考 えられる。

また，水噴流に回転力を与えている旋回ノズルの方 が, 供給した給水温度が低いこともあり, 円型ノズル に比べて水流速の遅い範囲でも高い空気質量割合で 安定作動することができた.

\section{$5 \cdot 5$ 給水温度による旋回ノズル性能の比較実硂}

図 12 に各種旋回ノズルの最大作動空気質量割合 $W_{g}$ と理想状態を仮定した遠心力の関係を示す. 実 験は, 蒸気通過出口面積 $A_{S}=77.5 \mathrm{~mm}^{2}$, 水流速 $j_{W}=17.1 \mathrm{~m} / \mathrm{s}, 3$ 種類の給水温度【条件 $1: T_{W}=21.8$ $\sim 24.0^{\circ} \mathrm{C}$, 条件 $2: T_{W}=14.3 \sim 15.7^{\circ} \mathrm{C}$, 条件 $3: T_{W}=4.9$ $\sim 7.0^{\circ} \mathrm{C}$ 】で行った.

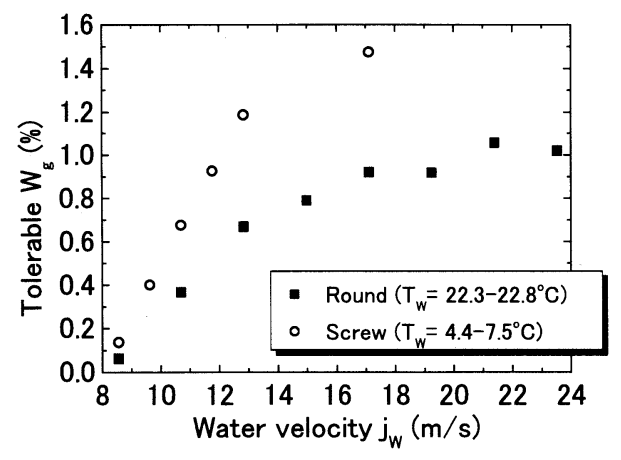

Fig. 11 Relation between tolerable air mass concentration and water velocity (screw)

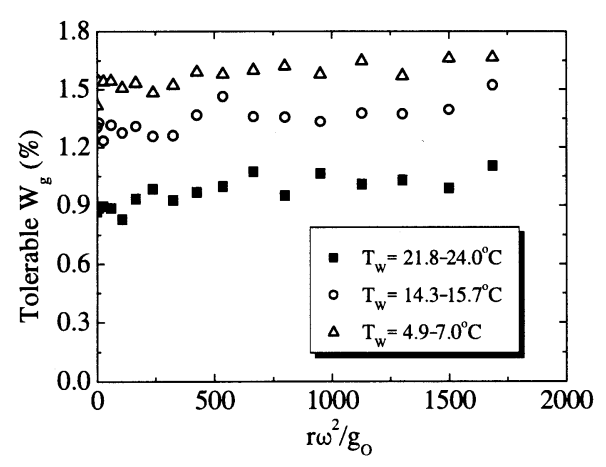

Fig. 12 Relation between tolerable air mass concentration and centrifugal force (screw)
図中の各プロット点は, 図 5 の異なる 16 本の渦流棒 を挿入した各旋回ノズルにおいて安定作動する最大 空気質量割合を示している. 図より, 給水温度が低く なるに従って, より空気質量割合の高い領域で作動で きている様子が分かる. 具体的に遠心力 0 の点を比較 すると, 条件 2 は条件 1 よりも給水温度が低いため $W_{g}=0.42 \%$ 、条件 3 は条件 1 よりもさらに低いため $W_{g}=0.55 \%$ 高いことが分かる. これは, 給水温度が低 くなったことで, 蒸気の凝縮する界面の温度が低下し て, 蒸気の水噴流表面への凝縮が促進されたため, より多くの空気を混入させても安定作動できたと考 えられる.

また, 図 12 に示すように遠心力が増加するに従い, 安定作動できる最大空気質量割合が徐々に増加する 傾向を示した. 具体的に遠心力 0 と実験範囲内で遠心 力が最大の点を比較すると, 条件 1 で $W_{g}=0.22 \%$, 条 件 2 で $W_{g}=0.23 \%$, 条件 3 で $W_{g}=0.25 \%$ の改善があっ た.このことから, 給水温度が異なっても改善できる 空気質量割合の増加はほぼ等しく, 旋回ノズル自身が 持つ性能にあまり影響しないことが分かる.

\section{$5 \cdot 6$ 各蒸呅通過出口面稓における旋回ノスル性能の}

比較実臨 図 13 に蒸気通過出口面積を変化させた 場合の 2 回転の旋回ノズルの空気質量割合 $W_{g}$ と遠心 力の関係を示す. 実験は, 蒸気流量一定とし 4 種類の 蒸気通過出口面積 $A_{S}=70.1 \mathrm{~mm}^{2}, A_{S}=77.5 \mathrm{~mm}^{2}$, $A_{S}=88.6 \mathrm{~mm}^{2}, A_{S}=100.4 \mathrm{~mm}^{2}$, 水流速 $j_{W}=17.1 \mathrm{~m} / \mathrm{s}$, 給水温 度 $T_{W}=14.1 \sim 16.6^{\circ} \mathrm{C}$ 範囲で行った.

蒸気通過出口面積が狭くなるに従い，安定作動でき る最大空気質量割合が大きくなることが分かる.これ は, 蒸気通過出口面積が狭くなることで流入する混合 気流速が増加して蒸気の水噴流表面への凝縮が促進さ れるためだと考えられる. 蒸気通過出口面積 $A_{S}=$

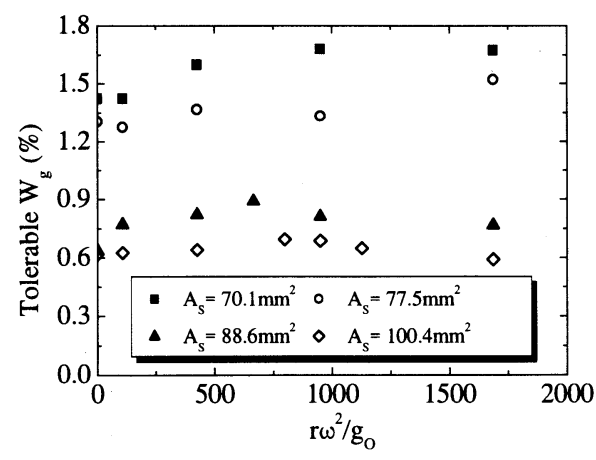

Fig. 13 Relation between tolerable air mass concentration and centrifugal force (screw) 
$70.1 \mathrm{~mm}^{2}$ および 77.5 $\mathrm{mm}^{2}$ では, 実験範井内で遠心力が 最大の場合が最も空気の影響に強くなった. この場合, まだピークに達していないので, 更に大きな遠心力を 与えれば, 安定作動できる最大空気質量割合も増加す る可能性がある.

しかし， $A_{S}=88.6 \mathrm{~mm}^{2}$ および $100.4 \mathrm{~mm}^{2}$ では，遠心力 の小さな範囲で最も空気の影響に強くなるピークを持 つことが分かった. すなわち単に遠心力を大きくすれ ば空気の影響に強くなる訳ではないことを示している. 蒸気通過出口面積が大きくなると蒸気インジェク夕内 部に流入する混合気流速が遅くなる.この遅い蒸気流 では, 水流速の増加に伴い, 水噴流が遠心力によって 外側へ膨れる現象を抑え切れず，水噴流が外側スリー ブに接触することで蒸気インジェクタが不作動になる 可能性が考えられる.

\section{6. 結}

不凝縮ガスである空気が蒸気インジェク夕の性 能に与える影響について, 円型・星型・旋回ノズ ルを用いて（蒸気 + 空気）混合気実験を行い，以 下の結論を得た.

（1） 円型ノズルよりも星型ノズルの方が空気の 影響に弱い. 星型という形状が凝縮面近傍の 空気の拡散を制限する構造であり, 蒸気の水 噴流表面への凝縮を妨げることが考えられ る.

（2）水噴流に回転力を与えたことで, 不凝縮ガス （空気）の影響に強い構造が出現した。この 一つの理由として, 水噴流に回転力を与えたこと で蒸気より重い空気が外側へと排除され, 蒸気の 水噴流表面への凝縮を妨げる力が小さくなり, 凝 縮が促進されることが考えられる.
（3）水流速が速い範囲では, 高い空気質量割合の 範囲でも正常に作動することができた。これ は, 蒸気の凝縮する界面の温度が低下し, 蒸 気の水噴流表面への凝縮が促進されたため だと考えられる。

（4）蒸気インジェクタの性能は給水温度に大き く影響された，一方，旋回ノズル自身が持つ 不凝縮ガスに対する改善効果は, 給水温度に あまり影響されない。

（5）蒸気通過出口面積が狭くなるに従い，空気質 量割合の高い範囲でも蒸気インジェクタは 正常に作動することができた．また，蒸気通 過出口面積ごとに最も空気の影響に強い遠 心力は異なる.すなわち, 最も空気の影響に 強い遠心力は, 凝縮部蒸気流速に依存するこ とが明らかとなった.

\section{文献}

(1) Narabayashi, T., Mori, M., Nakamura, M., Ohmori, S., "Study on two-phase flow dynamics in steam injectors II..High-pressure tests using scale-models", Nuclear Engineering and Design, 200 (2000) , pp.261-271

(2) Narabayashi, T., Nei, H., Ozaki, O., Shioiri, A., Mizumachi, W., "Study on high-performance steam injector", (in Japanese), Trans. of JSME, B, 62-597, (1996-5), pp.1833-1840

(3) Osakabe,M. and Ikeda,N., "Condensation Heat Transfer in Wide Range of Non-condensing Gas Fraction", (in Japanese), Trans. of JSME, 69-685, (2003), pp.2107-2113 